\title{
Cognitive Ability of High School Students in Level of Thinking based on Bloom's Taxonomy Viewed from Intrapersonal Intelligence
}

\author{
$1^{\text {st }}$ Sutama ${ }^{1}, 2^{\text {nd }}$ Harun Joko Prayitno ${ }^{2}, 3^{\text {rd }}$ Sabar Narimo $^{3}, 4^{\text {th }}$ Diana Purwita Sari ${ }^{4}$ \\ \{sutama@ums.ac.id\} \\ Education Faculty, Universitas Muhammadiyah Surakarta
}

\begin{abstract}
This research aims to describe cognitive ability of high school students in level of thinking on Bloom's taxonomy. This research was qualitative research. The research subjects were students in SMA Negeri 1 Gemolong of 2018/2019 academic year. The selected students consisted of 6 students, i.e. two subjects of intrapersonal intelligence with category strong, average, and weak. The research instruments were questionnaire, problem solving tasks, and interview guidelines. Based on findings, subject with strong intrapersonal intelligence are able to choose and decide on formulas that can be used to solve problems, therefore they can complete tasks given correctly and in a relatively short time. Subject with average intrapersonal intelligence are able to apply the formula correctly, but the problem solving is still in the standard category. Subject with weak intrapersonal intelligence have a high self-assessment of being able to solve problems, but have not been right in choosing a formula.
\end{abstract}

Keywords: cognitive ability, level of thinking on Bloom's taxonomy, intrapersonal intelligence

\section{Introduction}

Having good understanding on mathematics plays an important role as a tool for solving complex problems. This means that individuals need to develop their mathematical abilities to be able to solve various problems in various situations. Stacey $[16,17]$ called this ability as a mathematical literacy ability, namely the ability to refer to the capacity to formulate, apply, and interpret mathematics into various contexts. Mathematical literacy refers to mathematical reasoning abilities and refers to the use of mathematical concepts, procedures, facts, and prediction of phenomena in everyday life [13]. There are international organizations that assess students'mathematical literacy ability at present, namely the Program for International Student Assessment (PISA). Indonesia has participated in PISA studies six times, namely during 20002015. The results of the latest PISA survey in 2015 ranked Indonesian students in 63 place out of 70 countries.

The low level of mathematics achievement was also experienced by SMA Negeri 1 Gemolong. This can be seen from the student grade report of class XII of 2018/2019 academic year, in which,there were $37 \%$ of students who have not met the minimum completeness criteria (final score less than 75) based on the final score. Based on the results of observations conducted at SMA Negeri 1 Gemolong, the teacher was not used to applying challenging math questions. 
Further, the researcher conducted pre-survey activity to determine the abilities and skills of students in solving mathematical problems. The pre-survey activity was conducted by carrying out task-based interviews to one of the students. The task given was similar to the previous assignments given by the teacher. Pre-survey results show that the student has not been able to complete the task correctly. This shows that the student does not have good mathematical literacy ability. A student can be said having good literacy when he is able to solve problems and apply the knowledge that has been obtained previously to new unknown situations [3]. The process of achieving good literacy requires good cognitive ability.

Cognitive ability is an individual thinking process that includes simple intellectual abilities and complex intellectual abilities [14]. According to Bloom's taxonomy revision [11] cognitive domains are classified into six levels, namely: remembering (level 1), understanding (level 2), applying (level 3), analyzing (level 4), evaluating (level 5), and creating ( level 6). Brookhart [5] explained that the cognitive domains consist of higher order thinking skills (HOTS) and lower order thinking skills (LOTS). Brookhart further explained that HOTS includes the ability to think critically, logically, reflective, metacognitive, and creatively, while LOTS includes the ability to remember and understand. Based on Brookhart's opinion, it is concluded that levels 4, 5 and 6 in Bloom's taxonomy revision are included in HOTS, while levels 1 and 2 are included in LOTS. Then, the researcher categorizes level 3 in the category of middle order thinking skills (MOTS). This is because level 3 is above the LOTS category and under the HOTS category.

Cognitive ability is closely related to individual intrapersonal intelligence. This is because intrapersonal intelligence is intelligence that lies in someone who is characterized by the ability to understand themselves (Armstrong, 2009). This good understanding of self helps individuals to be able to control themselves in responding to various situations, including solving problems. The examples of learning experiences of individuals who have strong intrapersonal intelligence include being independent, having an attitude of confidence, and being able to make important decisions for themselves [8]. Individuals who have average intrapersonal intelligence know their strengths and weaknesses, but they have not been able to maximize their strengths and have not been able to minimize the shortcomings. Habeeb \& Fatema [9] explained that individuals with weak intrapersonal intelligence have not been able to reflect on their own shortcomings in solving a problem.

Based on the previous description, cognitive ability and intrapersonal intelligence have an important role in problem solving. The researcher needs to conduct research related to students'cognitive ability in solving mathematical problems in terms of intrapersonal intelligence.

\section{Research methods}

This research was a qualitative research. This research was conducted in SMA Negeri 1 Gemolong, specifically on class XII of 2018/2019 academic year. Subject selection was done by purposive sampling. The researcher identified the participants and sites based on purposive sampling, namely based on places and people that can help the researcherto understand the central phenomenon [7]. First, the researcher selected six students with details of two students in each category of intrapersonal intelligence. The category of intrapersonal intelligence was obtained based on a questionnaire developed based on aspects and indicators written by Alder [1]. Second, the researcher conducted task-based interviews on pre determined subjects. The assignment instrument was given in the interview, as presented below. 


\section{The first assignment of task-based interview}

Given that regular T.ABCD pyramid has a base edge of $8 \mathrm{~cm}$ anda lateral edge of $8 \sqrt{2} \mathrm{~cm}$. Determine the distance of $B$ point to the $T D$ line!

The second assignment of task-based interview

Given that $A B C D . E F G H$ cube has a length of $8 \mathrm{~cm}$. Determine the distance of $E$ point to the $F D$ line!

The data validation of this research was carried out with time triangulation. The researcher conducted task-based interviews twice and the interviews were conducted at different times. Data analysis of this research was conducted reciprocally, which means that data collection, data reduction, data presentation, and conclusion can be made reciprocally [6]. Data collection activities until data analysis in this research are illustrated by Figure 1.

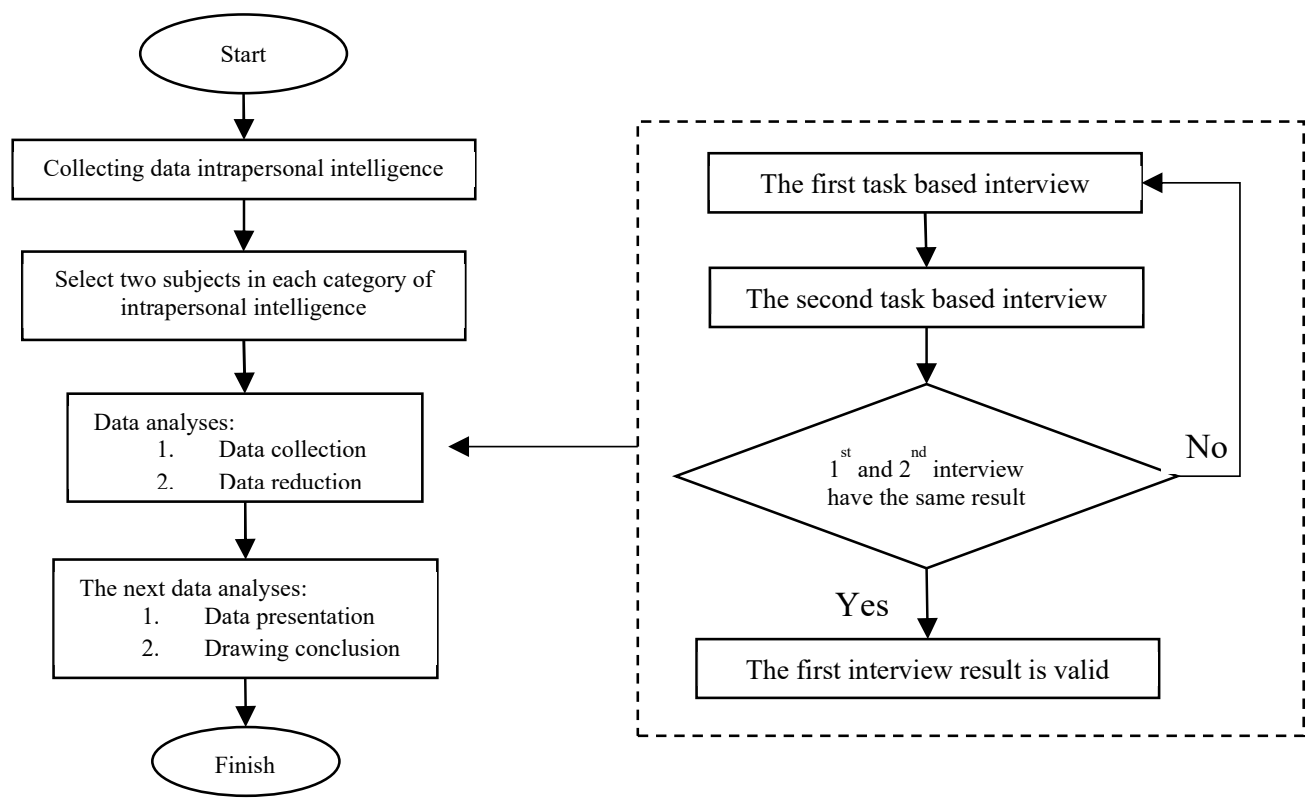

Figure 1. Data collection activities until data analysis in this research

\section{Research Results}

The result cognitive ability of high school students in level of thinking based on Bloom's taxonomy of each subject is shown as follows.

\subsection{Cognitive ability of high school students viewed from strong intrapersonal intelligence}

The subject could complete the task given correctly and the time used was relatively efficient. The subject involved aspects of remembering and understanding by reading problems 
given and looking for keywords in a problem that could be used to solve problems. The result of the subject's work when devising a plan is presented in Figure 2.

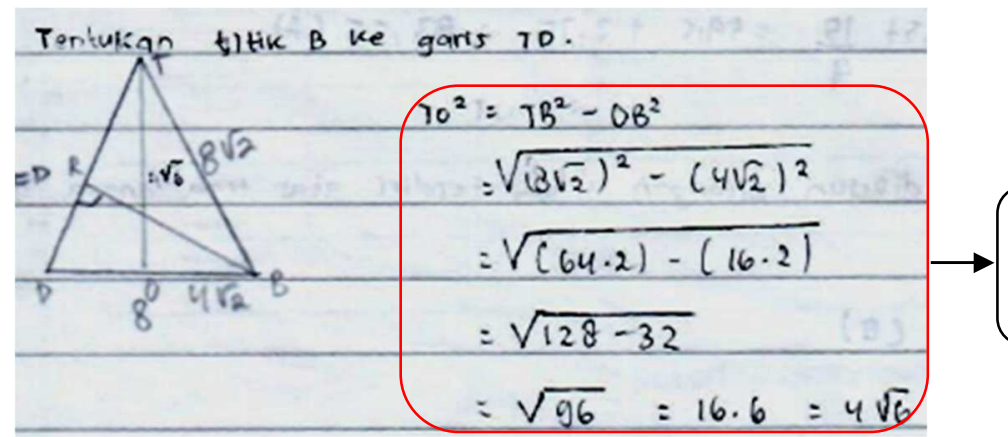

The subject found the keyword for problem solving

Figure 2.The result of the subject's work when devising a plan

Excerpts of interview with the subject when devising a plan are presented as follows $(\mathrm{R}=$ researcher; $\mathrm{S}=$ subject with strong intrapersonal intelligence students).

$\mathrm{R}$ : Have you been able to understand the problem given?

$\mathrm{S}$ : Yes, the problem that must be solved is to find the distance of $B R$.

$\mathrm{R}$ : What do you do to understand the problem given?

$\mathrm{S}$ : Finding the given data or keywords in the problem, formulas that can be used, and those needed in formula.

Based on Figure 2 and the excerpts of interview above, the subject developed what was remembered and understood to be a keyword that could help in solving the problem. This shows that the subject involved aspects of remembering, understanding, and planning well. The result of the subject's work when carrying out the plan is presented in Figure 3.

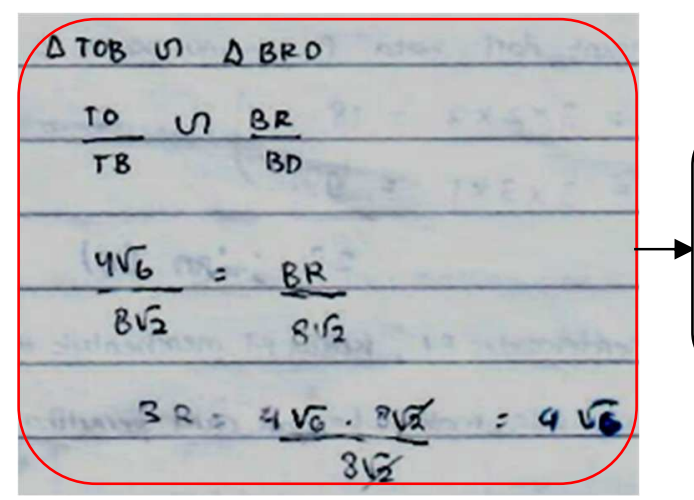

The subject was able to create formulas that can be used to solve problems. The subject can also analyze and evaluate what he/she has gained in understanding the problem so that the results of the work are correct.

Figure 3. Subject's work when carrying out the plan

The subject could analyze and evaluate well what he/she had gained in understanding the problem to help in finishing the solution as shown in Figure 3. The subject was also able to create a formula that could be used to solve problems correctly. This shows that the subject involved aspects of analyzing, evaluating, and creating well. 


\subsection{Cognitive ability of high school students viewed from average intrapersonal intelligence}

The subject could complete the task efficiently, but has not been able to complete the task given correctly. The subject involved aspects of remembering and understanding by reading the problems given. The result of the subject's work when devising a plan is shown in Figure 4.

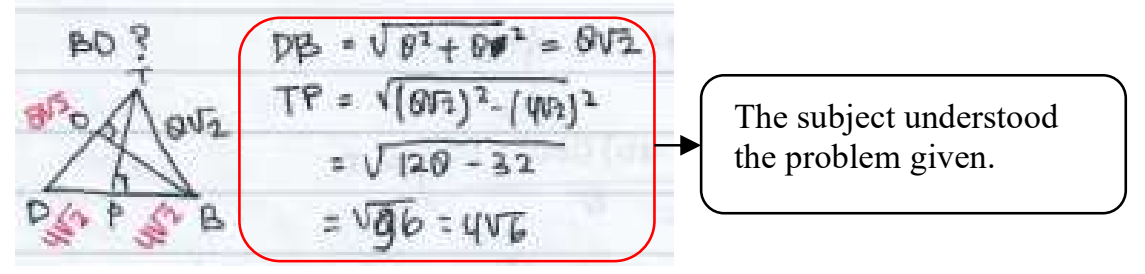

Figure 4. The result of the subject's work when devising a plan

Excerpts of interview with the subject when devising a plan are presented as follows $(\mathrm{R}=$ researcher; $\mathrm{A}=$ subject with average intrapersonal intelligence).

R: Can the assignments that I provide be completed in other ways?

A: I don't think I can.

R: What makes you sure that the assignment that I provide cannot be done in other ways?

A: Because that is the only formula given by the teacher.

Figure 4 shows that the subject involved aspects of remembering and understanding in problem solving. The subject applied the formula obtained from the teacher as stated in the interview. The result of the subject's work when carrying out the plan is shown in Figure 5.

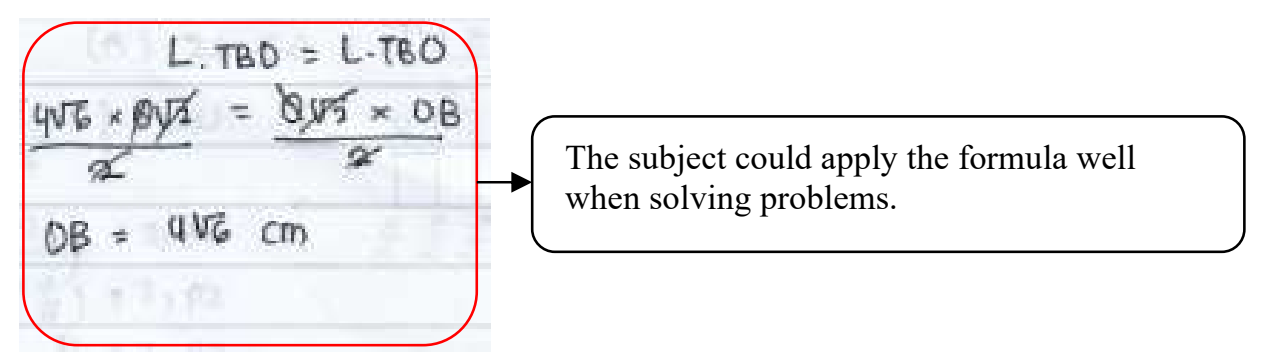

Figure 5.The result of the subject's work when carrying out the plan

The subject was able to apply the formula obtained correctly at the time of problem solving as shown in Figure 5. This shows that the subject involved the aspect of applying well. 


\subsection{Cognitive ability of high school students viewed from weak intrapersonal intelligence}

The subject has not completed the task given correctly. The subject involved remembering and understanding aspects by reading the problem given and writing what was known in the question on the answer sheet. The result of the subject's work when devising a plan is shown in Figure 6.

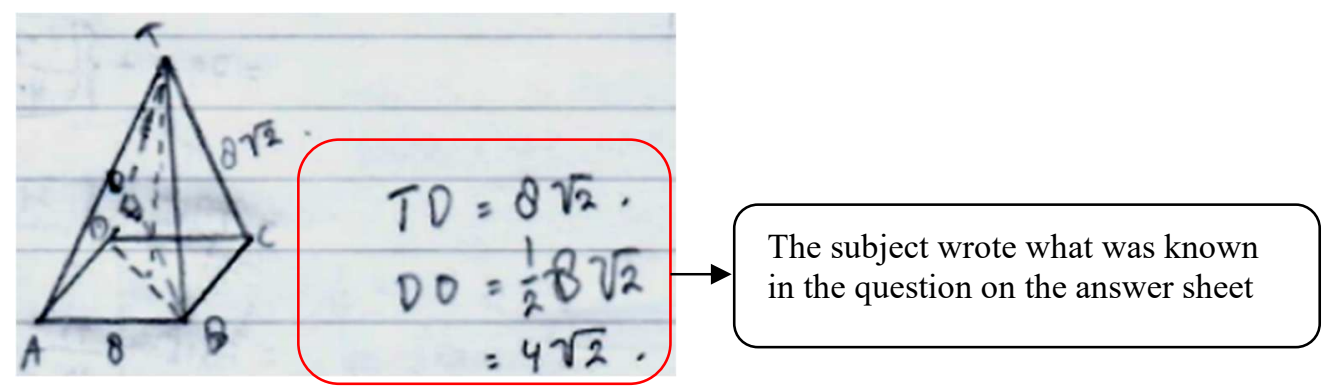

Figure 6. The result of the subject's work when devising a plan

Excerpts of interviews with the subject when devising a plan are presented as follows $(\mathrm{R}=$ researcher; $\mathrm{W}=$ subject with weak intrapersonal intelligence).

R: What are your plans to solve the problem given?

W: Specifies the distance $B$ to the $T D$ line with the Pythagorean formula.

$\mathrm{R}$ : Are you sure that the plan you chose is right?

W: Yes, in my opinion, it is the correct way.

Figure 6 above shows that the subject involved aspects of remembering and understanding. Based on the excerpts of the interview, the subject seemed confident that he/she was able to complete the task given. The result of the subject's work when carrying out the plan is shown in Figure 7.

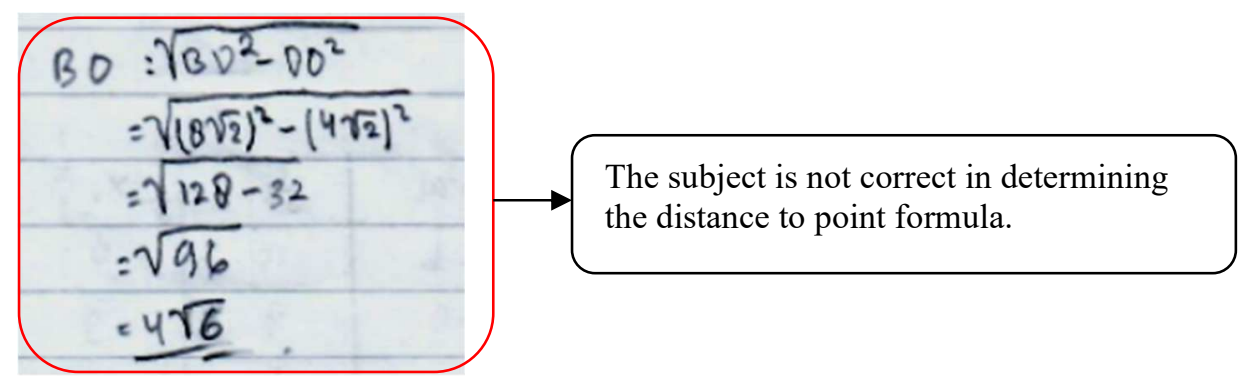

Figure 7.The result of the subject's work when carrying out the plan

Figure 7 shows that the subject was not correct in determining the formula that must be used. This shows that the subject involved aspects of remembering and understanding well, but they have not been able to develop what was remembered and understood at the level of applying. 


\section{Discussion}

The results of the research on the subject with strong intrapersonal intelligence show that the subject involves cognitive ability including remembering, understanding, applying, analyzing, evaluating, and creating. The subject involves aspects of remembering and understanding by reading problems given and looking for keywords in a problem that can be used to solve problems. The subject involves aspects of applying by combining aspects of remembering and understanding to find keywords that can help solve problems. The subject involves analyzing aspect by mentioning the solution plan in detail. The subject involves evaluating aspect by implementing the planning process appropriately. The subject involves creating aspect by choosing and deciding which formulas can be used to solve the problem.

Based on the results of data analysis, subject with strong intrapersonal intelligence is able to complete tasks that are given correctly in a relatively short period of time, and involve cognitive ability optimally. Individuals who involve cognitive ability in each problem solving allow individuals to develop to choose the right strategy to learn concepts and solve mathematical problems [2]. Subject with strong intrapersonal intelligence is also able to create formulas in completing their tasks. This is because students with strong intrapersonal intelligence are able to prepare their learning activities well [18]. The results of the research can be interpreted that the subject can solve the problem appropriately because they are able to find keywords for solution. Therefore, subject with strong intrapersonal intelligence include individuals with higher order thinking skills. The reason is it involves aspects of remembering, understanding, applying, analyzing, evaluating, and creating in problem solving.

The results of the research on the subject with average intrapersonal intelligence show that the subject involves cognitive ability including remembering, understanding, and applying. The subject involves aspects of remembering and understanding by reading the problems given and mentioning in detail the solution that will be carried out. The subject is also able to apply the formula correctly, but the problem solving is still in the standard category. This is because he/she is only able to apply the formula obtained from the teacher previously.

Based on the results of data analysis, the subject with average intrapersonal intelligence has not been able to develop aspects of remembering, understanding, and applying at the level of analysis. This is because the subject has not maximized the strength possessed in solving the problem. Strength and weakness are important aspects of intrapersonal intelligence. Individuals can fix the mistakes after knowing the strength and weakness possessed [19]. This is because intrapersonal intelligence is the ability of individuals to implement self-discipline in order to minimize the limitations they have [12]. The results of the research can be interpreted that the subject with average intrapersonal intelligence can solve the problem given, but it is less varied in its resolution. This is because the subject is only able to apply the formula previously obtained from the teacher. Thus, subject with average intrapersonal intelligence include individuals with middle order thinking skills. This is because it involves aspects of remembering, understanding, and applying in problem solving.

The results of the research on the subject with weak intrapersonal intelligence show that the subject is not correct in determining the formula that must be used. This shows that the subject involves aspects of remembering and understanding well, but he/she has not been able to develop what is remembered and understood at the level of applying.

Based on the results of data analysis, subject with weak intrapersonal intelligence has a high self-assessment on being capable of solving problems, but he/she has not been able to complete the task correctly. Similar results presented by In'am [10] that subjects with weak intrapersonal intelligence is lack self-awareness of cognitive ability performed. This is because intrapersonal 
intelligence is one of the core competencies in the intrapersonal domain. This competency has a strong relationship to the capacity of individuals in facing challenges [15]. This means that intrapersonal intelligence is also a determinant of success in solving problems. Thus, subjects with weak intrapersonal intelligence include individuals with low level thinking skills. It occurs because they involve aspects of remembering and understanding in problem solving.

\section{Conclusion}

Students with strong intrapersonal intelligence are able to choose and decide on formulas that can be used to solve problems, therefore, they can complete tasks given correctly and in a relatively short time. Thus, students with strong intrapersonal intelligence include individuals with higher order thinking skills. Students with average intrapersonal intelligence are able to apply the formula correctly, but the problem solving is still in the standard category (students have not been able to develop aspects of remembering, understanding, and applying the level of analysis). Thus, students with average intrapersonal intelligence include individuals with middle order thinking skills. Subjects with weak intrapersonal intelligence have a high self-assessment of being able to solve problems, but have not been right in choosing a formula, and therefore, that they have not been able to complete the task correctly. Thus, students with weak intrapersonal intelligence include individuals with lower order thinking skills.

\section{Acknowledgements}

The authors would like to thank to the principal of SMA Negeri 1 Gemolong for giving permission for researcher to collect data research. We also thank to all the parties which has helped the research process so that it goes according to plan. Our gratitude goes to the Directorate of Research and Community Service of the Directorate General for Research and Development of the Ministry of Research, Technology and Higher Education for Research and Development of the Ministry of Research, Technology and Higher Education which has assisted in funding the cost of multi-year research through the Graduate Research Grant Grants. Our thanks go to the Director of the Graduate School and the Head of Universitas Muhammadiyah Surakarta Research Institute and its staff, who have provided facilities and encouragement so that we can conduct research.

\section{References}

[1] Alder, H.: Boost Your Intelligence. Jakarta: Erlangga, (2001)

[2] Alzahrani, K. S.: Metacognition and Its Role in Mathematics Learning: an Exploration of the Perceptions of a Teacher and Students in a Secondary School. Vol. 12, pp. 521-537. IEJMEMathematics Education, (2017)

[3] Anwar, N. T., Waluya, B., and Supriyadi.: Abilities of Mathematical Literacy Based on SelfConfidence in Problem Based Learning with DAPIC Problem-Solving Process. Vol 7, pp 152160. Unnes Journal of Mathematics Education Research, (2018)

[4] Armstrong, T.: Multiple Intelligences in the Classroom. USA: Alexandria, (2009)

[5] Brookhart.: How to Assess Higher-Order Thinking Skills in Your Classroom. USA: ASCD Member Book, (2010)

[6] Budiyono.: Pengantar Metodologi Penelitian Pendidikan. Surakarta: UNS Press, (2017)

[7] Creswell, J. W.: Educational Research: Planning, Conducting, and Evaluating Quantitative and Qualitative Research. Upper Saddle River: Pearson Education, Inc., (2012) 
[8] Gangadevi, S., and Ravi.: Multiple Intelligence Based Curriculum to Enhance Inclusive Education to Bring Out Human Potential. Vol. 2, pp. 619-626. International Journal of Advanced Research, (2014)

[9] Habeeb, K. T., and Fatema, M.: Affect of Intrapersonal and Interpersonal Awareness Dimensions of Emotional Intelligence on Stress Management of Adolescents. Vol. 2, pp. 589-592. International Journal of Applied Research, (2016)

[10] In'am, A.: Euclidian Geometry Problem Solving Based on Metacognitive in Aspect of Awareness. Vol. 11, pp. 961-974. IEJME-Mathematics Education, (2016)

[11] Krathwol, D. R.: A Revision of Bloom's Taxonomy: An Overview. Vol. 41, pp. 212-218. Theory Into Practice, (2002)

[12] Nowack, K.: Sleep, Emotional Intelligence, and Interpersonal Effectiveness: Natural bedfellows. Vol. 69, pp. 66-79. Consulting Psychology Journal: Practice and Research, (2017)

[13] OECD.: PISA 2015 Assessment and Analytical Framework: Science, Reading, Mathematic and Financial Literacy. Paris: OECD Publishing, (2016)

[14] Sari, D. P., Usodo, B., and Subanti, S.: Metacognitive experience of mathematics education students in open start problem solving based on intrapersonal intelligence. Journal of Physics: Conference Series. 1008 012062, (2017)

[15] Singh, P.: Influence of Leaders' Intrapersonal Competencies on Employee Job Satisfaction. Vol. 12, pp. 1289-1302. International Business \& Economics Research Journal, (2013)

[16] Stacey, K.: Mathematical and Scientific Literacy Around The World. Vol. 33, pp. 1-16. Journal of Science and Mathematics Education in Southeast Asia, (2010)

[17] Stacey, K.: The PISA View of Mathematical Literacy in Indonesia. Vol. 2, pp. 95-126. Journal on Mathematics Education (IndoMS-JME), (2011)

[18] Sutama., Anif, S., Prayitno, H. J., and Sari, D. P.: Metacognitive knowledge of mathematics education students in analytical geometry of space. Journal of Physics: Conference Series. 1211 012056, (2018)

[19] Yerizon., Putra, A. A., and Subhan, M.: Mathematics Learning Instructional Development based on Discovery Learning for Students with Intrapersonal and Interpersonal Intelligence (Preliminary Research Stage). Vol. 13, pp. 97-101. International Electronic Journal of Mathematics Education, (2018) 